\title{
Evaluation and New Classification of Alveolar Bone Dehiscences Using Cone-beam Computed Tomography in vivo
}

\author{
Evaluación y Nueva Clasificación de las Dehicencias del Hueso Alveolar \\ Mediante Tomografía Computadorizada de Haz Cónico in vivo
}

Yan Yang*; Hui Yang"*; Hongyin Pan*; Jue $\mathrm{Xu}^{*}$ \& Tao Hu********

YANG, Y.; YANG, H.; PAN, H.; XU, J. \& HU, T. Evaluation and new classification of alveolar bone dehiscences using cone-beam computed tomography in vivo. Int. J. Morphol., 33(1):361-368, 2015.

SUMMARY: Alveolar bone dehiscences, which were "V" shaped defects related the margin of the alveolar bone, were common findings in different populations and decreased bony support of teeth. It was difficult to detect dehiscence during direct clinical examination. All of the previous studies on the prevalence of dehiscences were based on dry human skulls. In the current article, we evaluated the prevalence of dehiscences occurring naturally in a Chinese subpopulation, and prepared a classification of dehiscences using cone-beam computed tomography (CBCT). The high prevalence rate of dehiscences and different characteristics of each category suggest that it would be helpful for clinicians who perform periodontal surgery, endodontic surgery, implant surgery or orthodontic treatment to understand which teeth are most often associated with such bony defects, and to consider the effect of severe dehiscences on their diagnosis and treatment plan.

KEY WORDS: Alveolar bone loss; Periodontal disease; Cone-beam computed tomography; Oral surgery.

\section{INTRODUCTION}

The periodontium is a unique structure of the human body that provides support and nutrition for the teeth via the alveolus, periodontal ligament, cement and supporting gingiva. Alveolar defects, usually have negative effects on the prognosis of oral surgeries (Bjerklin \& Ericson, 2006).

A dehiscence is defined as a V-shaped defect located along the alveolar bone margin (BM) toward the apex, and is located on the buccal or lingual side of a tooth (Leung et al., 2010). The aetiology of dehiscences can be attributed to many factors, such as tooth ectopia, root projection, periodontal inflammation, frenum attachments, root vertical fracture and patient habits (Lustig et al., 2000; VilchezPerez et al., 2009). Dehiscences can be caused by one of the factors mentioned above or by the interactions of different factors.
The presence of dehiscences decreases the bony support for the teeth, which predisposes teeth to gingival recession, influences the rate and pattern of bone loss and complicates the outcome of oral surgeries. Alveolar bone with a dehiscence usually lacks a supporting layer of bone marrow, and depends on the periosteum and periodontal connective tissue for adequate nourishment and blood supply. Therefore, surgeries or treatment that remove or damage the periosteum, such as mucogingival surgery and endodontic surgery, will lead to even further resorption of the thin overlying plate of bone.

Dehiscences are present in different populations, with a reported prevalence ranging from $3.2 \%$ to $7.1 \%$ (Table I). Because of the high occurrence rate and undesirable effects of dehiscences, it is important that the dentists who perform oral surgeries or treatments and surgery have knowledge of the

Doctoral Candidate, Department of Operative Dentistry and Endodontics, State Key Laboratory of Oral Diseases, West China Hospital of Stomatology, Sichuan University, Sichuan, China.

** Lecturer, State Key Laboratory of Oral Diseases, West China Hospital of Stomatology, Sichuan University, Sichuan, China.

*** Professor, Department of Operative Dentistry and Endodontics, State Key Laboratory of Oral Diseases, West China Hospital of Stomatology, Sichuan University, Sichuan, China.

${ }^{* * * * *}$ Professor, Chair of Department of Preventive Dentistry, State Key Laboratory of Oral Diseases, West China Hospital of Stomatology, Sichuan University, Sichuan, China. 
effects of dehiscences on disease diagnosis and prognosis and on treatment planning in daily clinical practice. Considering the fact that bone dehiscences are covered by soft tissues, they are not visible to the naked eye and are usually undetectable. Occurring on the buccal or lingual side, dehiscences also escape routine radiographic diagnosis because of the overlapping images of the surrounding bony tissues. Hence, previous studies that investigated the prevalence of dehiscences were based merely on dry human skulls and on flap surgery on cadavers via direct evaluation (Rupprecht et al., 2001). The establishment of an accurate diagnosis of dehiscences without destroying soft tissues was reported only recently: cone-beam computed tomography (CBCT) was used to evaluate dehiscences in patients during orthodontic treatments (Janson et al., 2003). The accuracy of CBCT for identifying and measuring dehiscences has been confirmed in studies of artificially created alveolar bone defects (de-Azevedo-Vaz et al., 2013). Hence, CBCT has advantages for the evaluation of naturally occurring bony dehiscences in vivo (Ising et al., 2012).

Thus, the aim of this paper is to evaluate the prevalence, distribution and severity of dehiscences that occur naturally in humans by improving the method of dehiscence identification through CBCT and making a classification of dehiscences using a novel system based on the findings.

\section{MATERIAL AND METHOD}

Sample collection. Three hundred sixty four CBCT images from patients who received CBCT during routine examination were obtained from the Department of Oral Radiology, West China Hospital of Stomatology, Sichuan University, China. The study was approved by the Ethics Committee of the West China Hospital of Stomatology, and informed consent was obtained from the patients. CBCT images that included mixed dentition, single jaw, less than 10 teeth per jaw, metal prostheses, obvious trauma or tumor or cyst in the alveolar process, as well as those without a view of the entire tooth and surrounding alveolar bone, were excluded from the study. Third molars were also excluded. Finally, a total of 108 patients (2574 teeth) were obtained (Table II).

Radiographic technique. The CBCT images were produced at $80 \mathrm{kV}$ and $5.0 \mathrm{~mA}$ using a 3D Accuitomo scanner (J. Morita, Kyoto, Japan), with the voxel size of the images set at $0.125 \mathrm{~mm}$ and the slice thickness set at $1 \mathrm{~mm}$. CBCT was performed by an experienced oral radiologist using the manufacturer's protocol and radiographic standards to guarantee the quality of the images and to minimize the

Table I. Retrospection of the literature on prevalence of bone dehiscence.

\begin{tabular}{|c|c|c|c|c|c|}
\hline Studies & Population & Method & $\begin{array}{c}\text { Samples } \\
\text { (teeth) }\end{array}$ & Prevalence & Criteria used for dehiscence \\
\hline Davies et al. (1974) & British & Dry Skull & $\begin{array}{c}398 \\
(4143)\end{array}$ & $5.4 \%$ & $\begin{array}{l}\text { The crest of the buccal bone was at least } 4 \mathrm{~mm} \\
\text { apical to the crest of the interproximal bone. }\end{array}$ \\
\hline $\begin{array}{l}\text { Rupprecht etal. } \\
\text { (2001) }\end{array}$ & American & Dry Skull & $\begin{array}{c}146 \\
(3315)\end{array}$ & $4.1 \%$ & Davies et al. (1974) \\
\hline Edel (1981) & Bedouin & Dry Skull & $\begin{array}{l}\text { Max. } 37 \\
\text { Man. } 50\end{array}$ & $\begin{array}{l}\text { Max. } 2.1 \% \\
\text { Man. } 5.5 \%\end{array}$ & Davies et al. (1974) \\
\hline $\begin{array}{l}\text { Abdelmalek et al. } \\
\text { (1973) }\end{array}$ & Egyptian & Dry Skull & $\begin{array}{l}\text { Max. } 61 \\
\text { Man. } 93\end{array}$ & $\begin{array}{l}\text { Max. } 8.19 \% \\
\text { Man. } 21.5 \%\end{array}$ & $\begin{array}{l}\text { The absence of the alveolar cortical plate, in some } \\
\text { cases extending more than half of the root length. }\end{array}$ \\
\hline Larato (1970) & Mexican & Dry Skull & 108 & $3.2 \%$ & Not in detail. \\
\hline Urbani et al. (1991) & Italian & Dry Skull & 90 & $\begin{array}{l}\text { Max. } 6.3 \% \\
\text { Man. } 6.46 \%\end{array}$ & Not in detail. \\
\hline Tal (1983) & South & Dry Skull & Man. & Man. $7.1 \%$ & Not in detail. \\
\hline $\begin{array}{l}\text { Volchansky \& Vieira } \\
\text { (1981) }\end{array}$ & $\begin{array}{l}\text { South } \\
\text { African }\end{array}$ & Dry Skull & $\begin{array}{c}\text { Max. } \\
\text { Man. } 43\end{array}$ & $\begin{array}{l}\text { Max. } 5.6 \% \\
\text { Man. } 6.5 \%\end{array}$ & Not in detail. \\
\hline Yagci et al. (2012)* & --- & CBCT & --- & --- & $\begin{array}{l}\text { The alveolar bone height more than } 2 \mathrm{~mm} \text { from } \\
\text { the cement-enamel junction. }\end{array}$ \\
\hline $\begin{array}{l}\text { Evangelista } \text { et al. } \\
(2010)^{*}\end{array}$ & --- & CBCT & --- & --- & $\begin{array}{l}\text { The lack of facial or lingual cortical plates, which } \\
\text { results in exposing the cervical root surface and }\end{array}$ \\
\hline Leung et al. (2010)* & --- & CBCT & --- & --- & $\begin{array}{l}\text { A V-shaped defect along the BM, with the } \\
\text { alveolar bone height } 3 \mathrm{~mm} \text { or greater to the CEJ. }\end{array}$ \\
\hline Current Study & Chinese & $\mathrm{CBCT}$ & $\begin{array}{c}108 \\
(2574)\end{array}$ & $\begin{array}{l}8.51 \% \\
\text { Max. } 5.37 \% \\
\text { Man. } \\
11.55 \%\end{array}$ & $\begin{array}{l}\text { A V-shaped defect along the alveolar bone margin } \\
\text { apically with the lack of the margin, locates on the } \\
\text { buccal or lingual aspect of a tooth. }\end{array}$ \\
\hline
\end{tabular}

Max. indicates Maxillary, and Man. indicates Mandible. *= Means studies on dehiscences occurred during orthodontic treatment. None of the studies except the current one using CBCT investigated the prevalence of dehiscences in ethnic populations. 
Table II. Samples included for evaluation.

\begin{tabular}{lcc}
\hline Reasons for CBCT scanning & n & Percentage \\
\hline Assessment for implant surgery & 49 & 45.37 \\
Jaw disease (tumor or cyst) & 14 & 12.96 \\
Facial trauma & 11 & 10.19 \\
Assessment for orthognathic surgery & 9 & 8.33 \\
Assessment for orthodontic & 8 & 7.41 \\
Maxillary sinusitis & 4 & 3.70 \\
Temporal-mandibular joint disease & 4 & 3.70 \\
Salivary gland disease & 4 & 3.70 \\
Cleft lip and palate & 3 & 2.78 \\
Nasopharyngeal carcinoma & 2 & 1.85 \\
Total & 108 & 100 \\
\hline
\end{tabular}

radiation dosage delivered to the patients. Three-dimensional (3D) reconstructions were performed for each patient based on the CBCT images.

Evaluation of images. All of the analysis and 3D reconstructions of the $\mathrm{CBCT}$ data were performed using the in-built software (i-Dixel One Volume Viewer, Ver. 1.5.0) and viewed on a 32-in Sony LCD screen with a resolution of 1920 ' 1080 pixels in a dim light room.

The 3D volume-rendering mode was used to display the CBCT images to identify dehiscences in the buccal/lingual alveolar bone (Fig. 1A). Any V-shaped alveolar bony defect involving the bone margin and pointing to the root apex was identified as a dehiscence. After a dehiscence was diagnosed, the tooth root was evaluated in 2D cross-sectional images (Fig. 1B and 1C). First, the coronal (mesiodistal) plane of each tooth, which was determined by a line connecting the midpoints of the

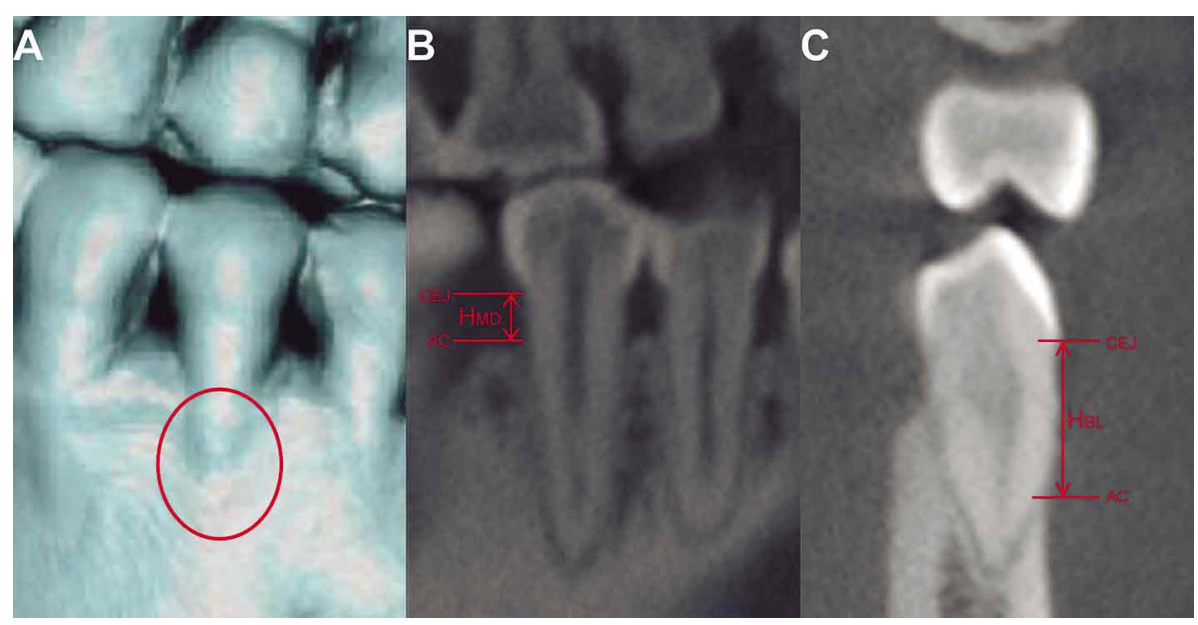

Fig. 1. CBCT 3D view and 2D views showing dehiscences. A, the 3D view on the buccal side of the tooth root. The red circle denotes the dehiscence. B, the mesial-distal view of the alveolar. $\mathrm{C}$, the buccolingual cross-sectional view of the dehiscence. $\mathrm{CEJ}=$ cement-enamel junction. $\mathrm{AC}=$ alveolar crest. $\mathrm{H}_{\mathrm{MD}}=$ the $\mathrm{CEJ}-\mathrm{AC}$ of the inter-proximal alveolar. $\mathrm{H}_{\mathrm{BL}}=$ the CEJ-AC of the dehiscence. mesial and distal marginal ridges, was placed perpendicular to the horizontal plane, and the alveolar bone height was measured from the cement-enamel junction (CEJ) to the alveolar crest (AC). The height was represented by HMD (the height of the CEJ-AC in the mesiodistal plane) (Fig. 1B). Subsequently, the sagittal (buccolingual) planes were placed perpendicular to the horizontal plane, and an alveolar defect was recorded when there was no cortical bone around the root in at least three consecutive views. The linear height of the CEJ to the AC in the buccolingual plane, which was represented by $\mathrm{H}_{\mathrm{BL}}$, was measured in three adjacent sagittal planes through the dehiscence, and the maximum height value was chosen (Fig. 1C). Finally, the height of the dehiscence $\left(\mathrm{H}_{\mathrm{D}}\right)$ was equal to HBL minus $\operatorname{HMD}\left(\mathrm{D}_{\mathrm{H}}=\mathrm{H}_{\mathrm{BL}}-\mathrm{H}_{\mathrm{MD}}\right) . \mathrm{D}_{\mathrm{H}}>0$ indicated the existence of an alveolar bone dehiscence, whereas $\mathrm{D}_{\mathrm{H}} \leq 0$ indicated a false-positive result of the $3 \mathrm{D}$ view.

Moreover, to distinguish dehiscences with different clinical manifestations in the present study, alveolar bone dehiscences were categorized into the following types and divisions, using a novel classification system based on the height of the dehiscence and other accompanying alveolar bone defects. All of these classifications were established using the sagittal planes (Fig. 2).

Class I: simple dehiscences located on one side (buccal or lingual) of the tooth, without any other alveolar bone defects. Division I: dehiscences of the coronal one-third of the root. Division II: dehiscences of the middle one-third of the root. Division III: dehiscences of the apical one-third of the root, without the involvement of the apical foramen.

In Class I dehiscences, the tooth root was divided into three equal portions, from the $\mathrm{CEJ}$ to the root apex. The coronal, middle and apical one-third of the root were classified as Division I, Division II and Division III, respectively.

Class II: dehiscences with periapical bone defects located on one side (buccal or lingual) of the tooth. Division I: dehiscences of the whole root, with the involvement of the apical foramen. Division II: dehiscences accompanied by periapical lesions. A periapical lesion was defined as a radiolucency associated with the apical part of 

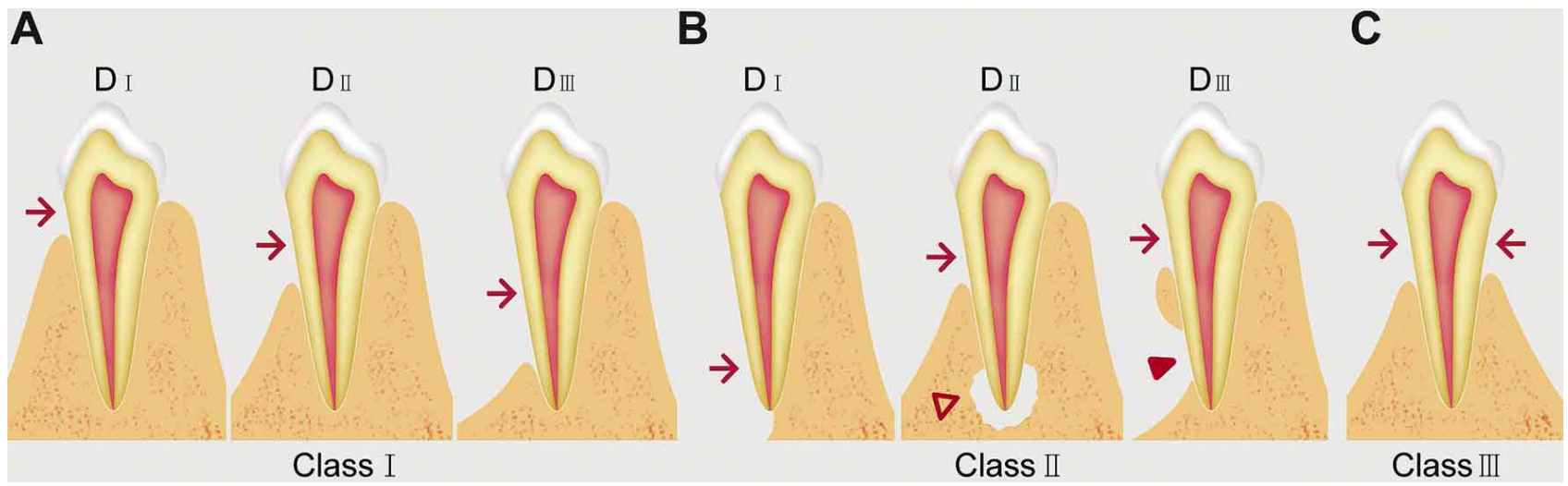

Fig. 2. Diagrammatic illustration indicating the classification of dehiscences based on the mesial-distal views. The red arrows indicate the alveolar dehiscences, the red solid triangles indicate the root fenestrations and the triangles denote the periapical lesions.

a root that exceeded at least twice the width of the periodontal ligament space (Lofthag-Hansen et al., 2007). Division III: dehiscences with fenestrations surrounding the root surface apically. Fenestration was identified as a defect in the alveolar bone without involvement of the alveolar margin (Pan et al., 2014).

Class III: dehiscences locating on both sides of the tooth. The classification is established according to the more severe side, referring to the divisions of Class I and Class II.

To distinguish Class I Division III from Class II Division I, more than three sagittal planes were used to detect the relationship between the margin of the defect and the apical foramen.

Two observers evaluated the teeth separately using the same criteria. When they disagreed, the third observer was introduced to evaluate the images with them and produce final consensus. Before the study, the three observers were trained in the same diagnostic criteria for the diagnosis of dehiscence and the details of this study, to improve baseline consistency.

Statistical analyses. Data analysis was conducted with Statistical Package for the Social Sciences (SPSS, version 18.0, Chicago, IL, USA) and the samples were confirmed with Gaussian distribution and homogeneity of variance. The prevalence of dehiscences in different teeth, different jaws, different sexes and different ages was evaluated using a regression analysis. One-way ANOVA followed by postTurkey or Bonferroni multiple comparison tests were used to analyze the differences in different teeth and different ages, student $t$ test for comparison the data of different jaws and different sex. Mean values with a difference of $\mathrm{P}<0.05$ were considered statistically significant.

\section{RESULTS}

The CBCT images of 2574 teeth in 108 patients were examined. Alveolar bone dehiscences were associated with $8.51 \%$ of all teeth (Table III), and at least one dehiscence was identified in $75 \%$ of all patients.

The intra-oral distribution of these defects is shown in Table IV. The distributions of dehiscences according to jaw and tooth type were calculated; $11.55 \%$ of dehiscences were observed on mandibles, whereas $5.37 \%$ of dehiscences were observed on maxillaries. The teeth that were most commonly associated with dehiscences were the first mandibular premolars $(37.56 \%)$ and the mandibular canines (13.49\%) $(\mathrm{P}=0.00)$. The first maxillary molars $(10.08 \%)$, second mandibular premolars $(9.95 \%)$ and first maxillary premolars $(8.65 \%)$ followed, albeit without statistically significant differences between any two of these three groups. Women had more alveolar bone dehiscences $(10.8 \%$ vs. $7.03 \%)$ than men $(\mathrm{P}=0.00)$ (Table III).

Most of the dehiscences were found in the buccal alveolar plates $(96.80 \%)$, and only $5.02 \%$ were found in the palatal or lingual side.

The dehiscences were classified into three types. The prevalence of dehiscences according to the different classifications is listed in Table V. Class I was the most frequent type $(86.03 \%)$, followed by Class II $(7.31 \%)$ and Class III (6.39\%). In Class I, and considering the specific part of the root involved, Division II was the most common subtype (42.47\%), followed by Division I (26.03\%) and Division III (17.35\%). In Class II, which includes periapical bone defects, the most common type was Division III (5.94\%), followed by Division I (0.91\%) and Division II (0.46\%). (P= 0.00$)$ 
Table III. Distribution of dehiscences according to sex.

\begin{tabular}{lccc}
\hline Sex & No. & n & Prevalence (\%) \\
\hline Male & 1565 & 110 & 7.03 \\
Female & 1009 & 109 & 10.80 \\
Total & 2574 & 219 & 8.51 \\
\hline
\end{tabular}

No. $=$ number of teeth calculated. $n=$ number of teeth with dehiscences.

Table IV. Distribution of dehiscences according to jaw and tooth type.

\begin{tabular}{llcccccccc}
\hline & Tooth type & $\mathbf{1}$ & $\mathbf{2}$ & $\mathbf{3}$ & $\mathbf{4}$ & $\mathbf{5}$ & $\mathbf{6}$ & $\mathbf{7}$ & Total \\
\hline Max. & No. & 190 & 205 & 207 & 208 & 200 & 129 & 128 & 1267 \\
& $\mathrm{n}$ & 6 & 7 & 15 & 18 & 9 & 13 & 0 & 68 \\
& Prevalence & 3.16 & 3.41 & 7.25 & 8.65 & 4.50 & 10.08 & 0 & 5.37 \\
Man. & No. & 209 & 215 & 215 & 213 & 201 & 135 & 119 & 1307 \\
& $\mathrm{n}$ & 6 & 5 & 29 & 80 & 20 & 10 & 1 & 151 \\
& Prevalence & 2.87 & 2.33 & 13.49 & $37.56^{*}$ & 9.95 & 7.41 & 0.84 & 11.55
\end{tabular}

* = Significant difference from any other group, $\mathrm{P}<0.05$. No.= number of teeth calculated. $\mathrm{n}=$ number of teeth with dehiscences. Max. indicates Maxillary and Man. indicates Mandible.

Table V. Distribution of dehiscences according to classification.

\begin{tabular}{cccccc}
\hline Type & & n & \multicolumn{3}{c}{ Percentage (\%) } \\
\hline Class I & DI & 57 & 189 & 26.03 & 86.30 \\
& DII & 93 & & 42.47 & --- \\
& DIII & 38 & & 17.35 & --- \\
Class II & DI & 2 & 16 & 0.91 & 7.31 \\
& DII & 1 & & 0.46 & --- \\
& DIII & 13 & & 5.94 & --- \\
Class III & --- & 14 & 14 & 6.39 & 6.39 \\
\hline
\end{tabular}

$\mathrm{n}=$ number of teeth with dehiscence.

\section{DISCUSSION}

As a routine dental radiography modality, $\mathrm{CBCT}$ has the potential to identify periodontal and alveolar defects without distortion, which is seen commonly in a panoramic radiograph. Compared with conventional radiography, CBCT enables the understanding of the morphology and the measuring of the size of alveolar defects. Previous studies (Enhos et al., 2012; Evangelista et al., 2010; Yagci et al., 2012) have used CBCT to measure the alveolar bone and detect dehiscences via axial and cross-sectional imaging. Leung et al., evaluated the accuracy and reliability of CBCT 3D constructions for measuring alveolar bone height and defects via direct measurements in 3D images. To facilitate the investigation of a large number of samples, we improved the method by combining the CBCT 3D constructions with 2D sections. Preliminary screenings were performed according to the 3D images. Subsequently, the 2D sections were used to exclude false-positive results, including thin bone coverage and horizontal resorptions and fenestrations, which were mistaken for dehiscences on 3D views. Finally, a definitive diagnosis and classification were established.

In previous studies on dehiscence that used CBCT, the method applied was usually direct measurements of CEJAC (Leung et al.), which was feasible for samples without horizontal resorption. However, the absorption of the alveolus would lead to false-positive results. Therefore, we improved the method by excluding the effect of horizontal resorption (Fig. 1).

Among the 2574 teeth examined, $8.6 \%$ had alveolar bone dehiscences. This was somewhat higher than the 3.2\% to $7.1 \%$ reported in the previous literature, which investigated dry human skulls among various ethnic groups (Table?). There are various explanations for this difference, including the racial differences suggested by most investigators, the various criteria used for the diagnosis of dehiscences, discrepancies between dry skulls and CBCT images, etc. 
Rupperecht et al. and Tal (1983) indicated that the different diagnostic criteria used by different authors may have had an additional effect on their results, making consensus difficult to reach. The definitions of dehiscence varied from a deficiency in alveolar bone resulting in the absence of alveolar cortical plate to a denuded root. The dimensions of dehiscences ranged from $1 \mathrm{~mm}$ to $4 \mathrm{~mm}$ or more from CEJ to AC. These differences in definitions and criteria may explain some of the variability in the distribution and prevalence of dehiscences observed among studies. Therefore, according to previous studies, we have emphasized the main characteristics of all the dehiscences, which could be described as a V-shaped defect located along the alveolar bone margin, together with the denuded areas involving the alveolar bone margin. The $\mathrm{V}$ shape is critical for the differentiation of dehiscence from horizontal bone loss and $\mathrm{U}$-shaped defects. The absence of the bone margin is used to distinguish dehiscence from fenestration, which is a window-like defect of the alveolar bone without the involvement of the alveolar margin (Pan et al.). Hence, in our study, an alveolar bone dehiscence was defined as a bony defect of the alveolar unit that appears as a V-shaped defect along the alveolar bone apically, lacks a margin and is located on the buccal or lingual side of a tooth. This definition was a combination of all previous definitions, and was not limited by the CEJ-AC length of the defect. As a result, it may lead to a higher prevalence of dehiscences than that reported in previous studies.

Moreover, as the alveolar bone plates in dried skulls may be physically damaged after exposure to soil, air and dissection, which may destroy the "V" shape of dehiscences, the prevalence of this phenomenon in those studies might be different from that observed in this in vivo study. Different ethnic backgrounds, preservation methods and acquisition methods would also affect the extent of bone erosion.

In the present study, dehiscences were more frequent in the mandible than in the maxilla. The most commonly associated teeth were the first mandibular premolars and mandibular canines. These findings were in agreement with those of previous reports (Rupprecht et al.; Davies et al., 1974), and indicated that more attention should be paid to the teeth mentioned above. Alveolar defects were found frequently on the buccal or labial surfaces in this study and in previous ones (Rupprecht et al.; Edel, 1981). In addition, the defects $(5.02 \%)$ were also found on the lingual or palatal aspect of the root. These results are consistent with the investigations of Rupperecht et al., and Evangelista et al.

Dehiscences occurred more frequently in women than in men. However, only one other study reported that dehiscences were more frequent in women, without statistical support (Rupprecht et al.). Although this could be attributed to the thinner alveolar bone of women, further studies are needed to assess this issue. In the present study, dehiscences were found most frequently on mandibular first premolars in all age groups, which was consistent with the study reported by Davies et al.. However, there was no statistically significant difference between any two age groups. This may indicate that age is not an important cause of dehiscences.

According to the literature, different criteria were used to detect dehiscences, and little information about the size or type of dehiscence was provided. Mild dehiscences may exist, without symptoms. However, severe dehiscences can result in further periodontal breakdown and aesthetic complications (Cardaropoli \& Gaveglio, 2007). According to the new classification suggested in this study, alveolar bone dehiscences were classified into three classes, depending on the size of the dehiscences or whether the dehiscences were accompanied by any other alveolar bone defect.

In Class I, simple dehiscences that occurred on one side of the teeth were then sorted into three divisions, depending on the range of the dehiscences. It was reported that the root surface located between the gingival margin and the alveolar bone margin is attached tightly by a long connective tissue (Löst, 1984). Hence, Class I Division I (26.03\%), which was the mildest condition among all the dehiscences, may have no symptoms or signs. Class I Division II (42.47\%) may have some signs of gingival recession, leading to various degrees of aesthetic problems, but may be painless or lack loosening because of the support from the bone and long connective tissue. The three divisions accounted for most of the dehiscences, which implies that most of the patients with dehiscences have no chief complaint or obvious signs. Class I Division III may have some aesthetic or lingual-buccal loosening problems, albeit not severe because of the remaining support from the connective tissue and the bone. Dehiscences located on both sides of the tooth were classified as Class III, whose effect will be determined by the two defects.

In the present study, dehiscences with periapical lesions were also detected; these may lead to pathological changes. Class II Division I included dehiscences of the whole root involving the root foramen, which may yield no pathological changes for a long time because of the support and nutrition from the connective tissue. However, once inflammation or trauma occurs in the teeth, severe effects, such as tooth mobility, retrograde pulpitis or loss of the tooth, will occur. Class II Division II included dehiscences with any periapical bone defect combined with inflammation, which were often caused by pulpitis. In cases with spreading 
of the periapical lesion, it is easy to break through the bone between the dehiscence and periapical lesion, leading to periodontal- endodontic combined lesions. Class II Division I and Division II represented only three cases among the teeth studied here. It is assumed that most of the teeth with these classes of dehiscences could not be included in the classification because of natural loss or extraction in older patients. Class II Division III represented the combination of dehiscence and fenestration, and is complex. A combination with the classification of fenestration provided in the study of Pan et al., should be considered under specific conditions.

During mucogingival flap surgery, the root surface should not be exposed, and an adequate blood supply to the soft tissue coverage of the defect should be ensured (Yagci et al.). Dehiscences are sometimes located in areas with a relatively thin mucosa, which may result in insufficient blood supply to the flap. Therefore, a full-thickness flap is suggested to maximize blood supply to the overlying tissue at the defect site.

Kim \& Kratchman, (2006) indicated that deficiency of marginal bone tissue has a significant effect on the prognosis of endodontic microsurgery. A buccal bone plate that covered the teeth for $>3 \mathrm{~mm}$ was expected to yield a favorable outcome. Once an alveolar bone defect is found, a comprehensive treatment plan including endodontic microsurgery is suggested.

Spray et al. (2000) indicated that an alveolar bone wall with a thickness greater than $2 \mathrm{~mm}$ was crucial for the successful long-term outcomes of implants. Merheb et al. (2010) reported that a terminal dehiscence defect would influence the stability of the implant. For patients with a thin alveolar wall or bone defect, a thorough examination and adjunctive bone augmentation are recommended (Zekry et al., 2013). Considering the fact that peri-implant bone defects are not visible to the naked eye and traditional radiography, $\mathrm{CBCT}$ is of paramount importance to detect such defects (de-Azevedo-Vaz et al.).

The possible presence of dehiscences also requires attention before orthodontic treatment. Gingiva augmentation prior to orthodontic therapy should be considered for all teeth with a gingival complex. Severe dehiscences, on the other hand, can be partly improved by a combination of guided tissue regeneration and connective tissue graft. This is of even greater importance for teeth in which clinical examination or CBCT images indicate the presence of underlying dehiscences.

There was a lack of report on clinical signs of dehiscences in the present literature. Combining dehiscences detected from the existing CBCT images with the clinical manifestations would make clinically detecting of dehiscence more targeted. It will be helpful to avoid the excessive application of CBCT through prejudgment of the severity of dehiscence type clinically, which is the next research purpose of this subject.

\section{ACKNOWLEDGEMENTS}

This work was supported by the Key Clinical Program of the Ministry of Health of China. The funding body had no role in the study design, data collection and analysis, decision to publish or preparation of the manuscript. We also gratefully thank Zhili Zhao, PhD, School and Hospital of Stomatology, Wuhan University, Wuhan, China for valuable suggestions and enthusiastic support.

YANG, Y.; YANG, H.; PAN, H.; XU, J. \& HU, T. Evaluación y nueva clasificación de las dehicencias del hueso alveolar mediante tomografía computadorizada de haz cónico. Int. J. Morphol., 33(1):361-368, 2015.

RESUMEN: Las dehiscencias óseas alveolares, con forma de "V" en el margen del hueso alveolar, son hallazgos comunes en diferentes poblaciones y provocan una disminución del soporte óseo de los dientes. La dehiscencia fue difícil de identificar durante la exploración clínica directa. Todos los estudios anteriores sobre la prevalencia de dehiscencia se basaron en cráneos humanos secos. En el presente artículo, se evaluó la prevalencia de dehiscencia natural ocurrido en una subpoblación de China. Realizamos una clasificación de las dehiscencias mediante tomografía computarizada cone-beam (TCCB). La alta prevalencia de dehiscencias y las diferentes características de cada categoría sugieren que esta clasificación sería de gran ayuda para los médicos que realizan cirugía periodontal, endodóntica, cirugía de implantes o tratamiento de ortodoncia, permitiendo informar sobre que dientes están más frecuentemente asociados con tales defectos óseos, y poder considerar los efectos severos de las dehiscencias severas en el diagnóstico y el plan de tratamiento.

PALABRAS CLAVE: Pérdida de hueso alveolar; Enfermedad periodontal; Tomografía computadorizada de haz cónico; Cirugía oral. 


\section{REFERENCES}

Abdelmalek, R. G. \& Bissada, N. F. Incidence and distribution of alveolar bony dehiscence and fenestration in dry human Egyptian jaws. $J$. Periodontol., 44(9):586-8, 1973.

Bjerklin, K. \& Ericson, S. How a computerized tomography examination changed the treatment plans of 80 children with retained and ectopically positioned maxillary canines. Angle Orthod., 76(1):4351, 2006.

Cardaropoli, D. \& Gaveglio, L. The influence of orthodontic movement on periodontal tissues level. Semin. Orthod., 13(4):234-45, 2007.

Davies, R. M.; Downer, M. C.; Hull, P. S. \& Lennon, M. A. Alveolar defects in human skulls. J. Clin. Periodontol., 1(2):107-11, 1974.

de-Azevedo-Vaz, S. L.; Vasconcelos, Kde. F.; Neves, F. S.; Melo, S. L.; Campos, P. S. \& Haiter-Neto, F. Detection of periimplant fenestration and dehiscence with the use of two scan modes and the smallest voxel sizes of a cone-beam computed tomography device. Oral Surg. Oral Med. Oral Pathol. Oral Radiol., 115(1):121-7, 2013.

Edel, A. Alveolar bone fenestrations and dehiscences in dry Bedouin jaws. J. Clin. Periodontol., 8(6):491-9, 1981.

Enhos, S.; Uysal, T.; Yagci, A.; Veli, I.; Ucar, F. I. \& Ozer, T. Dehiscence and fenestration in patients with different vertical growth patterns assessed with cone-beam computed tomography. Angle Orthod., 82(5):868-74, 2012.

Evangelista, K.; Vasconcelos, Kde. F.; Bumann, A.; Hirsch, E.; Nitka, M. \& Silva, M. A. Dehiscence and fenestration in patients with Class I and Class II Division 1 malocclusion assessed with conebeam computed tomography. Am. J. Orthod. Dentofacial Orthop., 138(2):133.e1-7, 2010.

Ising, N.; Kim, K. B.; Araujo, E. \& Buschang, P. Evaluation of dehiscences using cone beam computed tomography. Angle Orthod., 82(1):122-30, 2012.

Janson, G.; Bombonatti, R.; Brandão, A. G.; Henriques, J. F. \& de Freitas, M. R. Comparative radiographic evaluation of the alveolar bone crest after orthodontic treatment. Am. J. Orthod. Dentofacial Orthop., 124(2):157-64, 2003.

Kim, S. \& Kratchman, S. Modern endodontic surgery concepts and practice: a review. J. Endod., 32(7):601-23, 2006.

Larato, D. Alveolar plate fenestrations and dehiscences of the human skull. Oral Surg. Oral Med. Oral Pathol., 29(6):816-9, 1970.

Leung, C. C.; Palomo, L.; Griffith, R. \& Hans, M. G. Accuracy and reliability of cone-beam computed tomography for measuring alveolar bone height and detecting bony dehiscences and fenestrations. Am. J. Orthod. Dentofacial Orthop., 13714 Suppl.):S109-19, 2010.

Lofthag-Hansen, S.; Huumonen, S.; Gröndahl, K. \& Gröndahl, H. G. Limited cone-beam CT and intraoral radiography for the diagnosis of periapical pathology. Oral Surg. Oral Med. Oral Pathol. Oral Radiol. Endod., 103(1):114-9, 2007.
Löst, C. Depth of alveolar bone dehiscences in relation to gingival recessions. J. Clin. Periodontol., 11(9):583-9, 1984.

Lustig, J. P.; Tamse, A. \& Fuss, Z. Pattern of bone resorption in vertically fractured, endodontically treated teeth. Oral Surg. Oral Med. Oral Pathol. Oral Radiol. Endod., 90(2):224-7, 2000.

Merheb, J.; Coucke, W.; Jacobs, R.; Naert, I. \& Quirynen, M. Influence of bony defects on implant stability. Clin. Oral Implants Res., 21(9):919-23, 2010.

Pan, H. Y.; Yang, H.; Zhang, R.; Yang, Y. M.; Wang, H.; Hu, T. \& Dummer, P. M. Use of cone-beam computed tomography to evaluate the prevalence of root fenestration in a Chinese subpopulation. Int. Endod. J., 47(1):10-9, 2014.

Rupprecht, R. D.; Horning, G. M.; Nicoll, B. K. \& Cohen, M. E. Prevalence of dehiscences and fenestrations in modern American skulls. J. Periodontol., 72(6):722-9, 2001.

Spray, J. R.; Black, C. G.; Morris, H. F. \& Ochi, S. The influence of bone thickness on facial marginal bone response: stage 1 placement through stage 2 uncovering. Ann. Periodontol., 5(1):119-28, 2000.

Tal, H. Alveolar dehiscences and fenestrae in dried South African Negro mandibles. Am. J. Phys. Anthropol., 61(2):173-9, 1983.

Vilchez-Perez, M. A.; Fuster-Torres, M. A.; Figueiredo, R.; ValmasedaCastellón, E. \& Gay-Escoda, C. Periodontal health and lateral lower lip piercings: a split-mouth cross-sectional study. J. Clin. Periodontol., 36(7):558-63, 2009.

Volchansky, A. \& Vieira, E. Alveolar dehiscence and fenestration in dried South Africa Negro maxillae. J. Dent. Aorthodontic treatment to understand which teeth are most often associated with such bony defects, and to consider the effect of severe dehiscences on their diagnosis and treatment plan. J. Dent. Assoc. S. Afr., 36(10):701-4, 1981.

Yagci, A.; Veli, I.; Uysal, T.; Ucar, F. I.; Ozer, T. \& Enhos, S. Dehiscence and fenestration in skeletal Class I, II, and III malocclusions assessed with cone-beam computed tomography. Angle Orthod., 82(1):6774, 2012.

Zekry, A.; Wang, R.; Chau, A. C. \& Lang, N. P. Facial alveolar bone wall width - a cone-beam computed tomography study in Asians. Clin. Oral Implants Res., 25(2):194-206, 2014.

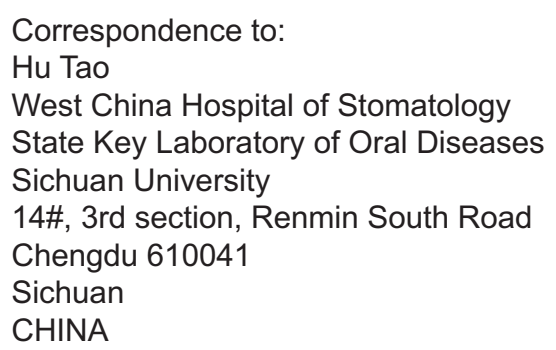

Email: hutao@scu.edu.cn

Received: 18-09-2014

Accepted: 30-12-2014 